Бородулькина Татьяна. Метафора руки как проективный материал в работе практического психолога/ Татьяна Бородулькина // East European Journal of Psycholinguistics. (2017). Lutsk: Lesya Ukrainka Eastern European National University. Vol. 4, No 1. - Pp. 17-29. [Электронный ресурс]. - Режим доступа: http://eepl.at.ua/load/volume_3_number_1_2017/borodulkina_t/153

или:

Borodulkina, Tetyana. (2017). The Hand Metaphor as a Projective Tool of Applied Psychologist. East European Journal of Psycholinguistics (2017), 4(1), 17-29. http://doi.org/10.5281/zenodo.824023

\title{
МЕТАФОРА РУКИ КАК ПРОЕКТИВНЫЙ МАТЕРИАЛ В РАБОТЕ ПРАКТИЧЕСКОГО ПСИХОЛОГА
}

АНОТАЦІЯ. У статті звертається увага на проблему науково-практичного обтрунтування використання метафоричних образів в якості проективного матеріалу в роботі практичного психолога. У результаті теоретичного аналізу автор описує метафору як проективний і терапевтичний інструмент, обтрунтовує необхідність звертання психологів до метафори, розглядає причини використання різноманітних метафор у психологічній практиці. Робиться акцент на розумінні метафори як засобі вираження та конструювання смислів, $у$ тому числі екзистенційних. На прикладі змістовного наповнення метафоричних асоціативних карт піднімається проблема науково-практичного обтрунтування метафоричних образів, щзо використовуються у психологічній практиці. Автор вважає метафору руки важливим проективним матеріалом у роботі психолога та необхідним змістовним наповненням такого психологічного терапевтичного інструменту як метафоричні асоціативні карти. $У$ результаті аналізу різноманітних досліджень символіки й значень руки, узагальнення досвіду використання зображення руки в практичній психологї (на матеріалі діагностичних методів $i$ різноманітних метафоричних асоціативних карт), а також на основі власного різноманітного досвіду практичної роботи автор запропонував робочу модель можливостей використання метафори руки як проективного матеріалу в роботі практичного психолога (на прикладi авторських метафоричних карт). 3 огляду на багатозначність, багатовимірність і відносну універсальність метафори руки, автор вважає, щзо залучення до психологічної практики очевидних (об'єктивних) і символічних характеристик руки дозволить практичним психологам прачювати з великим репертуаром психологічних запитів (проблеми фізичного й психічного здоров'я; вікового розвитку й старіння; взаємин; соиіального й професійного статусу; влади й підпорядкування; екзистенційні, моральні, изіннісно-смислові питання тощо). 
Ключові слова: метафора, метафоричні образи, візуальна метафора, метафоричні асочіативні карти, образ руки, метафора руки, практичні психологи.

\section{Tetyana Borodulkina. The Hand Metaphor as a projective tool of Applied Psychologist}

Abstract. Metaphorical images are viewed as a good projective tool in the work of applied psychologist. The author describes the use of metaphor both as projective and therapeutic tool. The paper substantiates the reasons for using various metaphors in psychological practice. A special attention is drawn to understanding metaphor as a means of expression and designing of senses, including the existential senses. First, metaphoric associative cards (MAC) with images are introduced as the media of psychological practice. They employ the metaphor of 'hand' as an important projective material in the work of the practical psychologist. The author discusses the symbolic nature of 'hand' and scientific background of using this image in applied psychology as diagnostic method along with various metaphoric cards. Results of the study proved that the objective use of the 'hand' metaphor facilitates the applied psychologists to overcome patients' psychological problems related to health, maturity and aging, sexual and parental relationships, social status. On the other hand, its symbolic application helps the psychologist find some solutions to the individual problems of power and subordination, violence and punishment, protection and posession, traumatic experience, stress coping and crisis overcoming strategies, mental health and ethical and moral existential issues.

Keywords: metaphor, metaphorical images, visual metaphor, Metaphoric Cards, the image of hand, the metaphor of hand, applied psychologist.

\section{Введение}

Метафора является одним из важных, необходимых и востребованных инструментов в психологической и психотерапевтической практике. Так, метафорические образы часто являются стимульным материалом в проективной диагностике, а разные виды метафор активно используются психологами в консультировании, коррекционной, развивающей, психотерапевтической и просветительской работе.

Обращение психологов к метафорическому, образному и символическому материалу не является случайным. Недаром Х. Ортега-и-Гассет отмечает, что «почти вся современная психологическая терминология - это чистая метафора» 
(Ортега-и-Гассет, 1990:76), а Л.И. Шрагина рассматривает метафору как универсальный инструмент для реализации функции понимания не только внешнего, но и внутреннего (психического) мира; средство активизации психической деятельности воспринимающего еe субъекта и средство эмоционального воздействия на человека. Через метафору человек общается со своим внутренним (идеальным) миром. Именно через сравнение с чем-то из реального мира человек вербализует свои часто неосознаваемые чувства и эмоциональные состояния, в результате чего - осознает их (Шрагина, 2016: 181207). Н. Пезешкиан обосновывает использование метафор в собственной психотерапевтической практике тем, что многим людям слишком трудно воспринимать психотерапевтическую тематику в абстрактном изложении, так как понимание собственных проблем скорее достигается благодаря наглядному, образному мышлению и эмоционально окрашенному воображению. А метафорический материал в виде примеров из жизни, мифов и притч, при целенаправленном их использовании, поможет, по его мнению, создать дистанцированное отношение к собственным проблемам (Пезешкиан, 2001:17$18)$.

О.А. Свирепо и О.С. Туманова отмечают устойчивую тенденцию обращения психологов к глубинным пластам подсознания, имеющего исключительно образный характер, для лечения различных психических расстройств. В связи с тем, что образ невербален, метафора не является чисто языковым феноменом. Переход на уровень языка авторы считают способностью посмотреть на событие со стороны, тогда как метафора - это взгляд на мир изнутри. Метафора, по мнению О.А. Свирепо и О.С. Тумановой, помогает человеку по-новому расставить акценты и переосмыслить собственный опыт, посмотреть на все со стороны; позволяет упростить сложную проблему и сделать ее более доступной для понимания. Метафору используют тогда, когда необходимо выразить то, что прямо высказать сложно (Свирепо, Туманова, 2004). 
Для нас, метафора интересна, прежде всего, как средство выражения, опредмечивания и конструирования смыслов, в том числе экзистенциальных. Считаем, что в психологической практике с помощью метафоры можно работать не только с внутренними переживаниями и конфликтами (часто неосознаваемыми), выводя их на более осознаваемый уровень, но и обсуждать экзистенциальные проблемы человека, вопросы его предназначения, самосовершенствования, личностного, профессионального и духовного развития.

В основе «работы» метафор лежат определенные психологические механизмы, среди которых И.В. Вачков выделяет: 1) экстраполяцию скрытых смыслов (когда у субъекта возникает возможность черпать из метафоры то содержание, которое отвечает его миропониманию и видению своих проблем); 2) пробуждение творческих ресурсов воображения; 3) семантическое опосредование (метафоры - связующее звено между семантическими пространствами психолога и клиента); 4) актуализацию архетипов (метафоры задействуют глубинные механизмы бессознательного за счет непривычных для разума архетипических элементов); 5) фасилитацию (метафоры облегчают осознание системы отношений между субъектами и снижают влияние отрицательных эмоций при получении болезненной для субъекта информации; они действуют намного мягче и деликатнее, чем многие другие средства психологического воздействия) (Вачков, 2006).

Наряду с вербальныли метафорами (миф, басня, сказка, притча, история, пример из жизни и др.) в психологической и психотерапевтической практике используются визуальные метафоры, под которыми О.А.Свирепо и О.С. Туманова понимают графическую передачу сообщения, построенную по принципу аналогии, сходства, сравнения. Это могут быть разнообразные изображения - важно, чтобы они были значимы, имели смысл для клиента. Авторы видят возможности использования визуальных метафор тогда, когда высказывание вслух какой-либо информации является для клиента чрезвычайно болезненным или невозможным. С их точки зрения, «подсознательные 
конфликты и внутренние переживания легче выразить с помощью зрительных образов, чем вербально, поскольку в данном случае отсутствует сознательная цензура» (Свирепо, Туманова, 2004:171).

Метафора в работе практического психолога часто становится проективным и терапевтическим инструментом. В связи с этим в психологии стало возможным говорить о терапевтической метафоре, которую, например, И.М. Михина понимает как действенное средство реконструкции ценностносмысловой сферы личности, влияющей на актуализацию еe творческого потенциала (Михина, 2003). Мы считаем, что в проективной работе психолога метафорический материал приобретает все свойства проективных стимулов, т.е. становится своего рода экраном, «на который респонденты «проецируют» свои характерные мыслительные процессы, потребности, тревоги и конфликты» (Анастази, Урбина, 2001:450).

Ярким примером терапевтической метафоры можно считать популярный среди современных практических психологов и психотерапевтов проективный инструмент - метафорические ассоциативные карты (МАК), которые чаще всего представляют собой наборы небольших картинок, рисунков, коллажей или фотографий (в состав некоторых МАК входят также схемы, слова и аффирмации).

В настоящий момент существует огромное количество немецких, израильских, украинских, российских, норвежских и др. МАК, но, на наш взгляд, далеко не каждый из появляющихся наборов ассоциативных карт можно отнести к полноценным качественным профессиональным психологическим инструментам. Считаем, что все существующие наборы МАК условно можно расположить на двухполюсной шкале: «MAK как подручнылй проективный материал»- «МАК как профессиональный психологический инструментарий». Одним из оснований отнесения МАК к профессиональному психологическому инструментарию считаем наличие определенной концепции, научнопрактического объяснения использования тех или иных метафорических образов в качестве главного содержательного наполнения МАК. Без такого обоснования 
МАК не будут цельным профессиональным инструментом, а будут лишь набором хаотичных, субъективно подобранных картинок, фотографий или слов, одним из вариативных подручных проективных материалов в работе психолога, наряду с любыми другими изображениями, предметами и т.д. Конечно, сам психолог будет решать, опираться ли ему в своей практике на предлагаемую автором концепцию МАК, или использовать МАК интуитивно, исходя из собственного понимания тех или иных метафор. В любом случае, считаем, что наличие теоретической концепции определяет структуру МАК, является «скелетом» того или иного набора МАК, а продуманная система значений метафорических образов, предлагаемая автором МАК в результате его научно-практического поиска, является отправной точкой в работе психолога, использующего в своей практике данный проективный инструмент.

Метафорические образы, используемые в МАК в качестве проективных стимулов, очень разнообразны. Наборы МАК можно условно разделить на две группы: МАК, в которых изображения связаны с разными метафорическими образами (например, немецкие МАК «ОН» М. Эгетмейера; украинские МАК «Креатив-1» Ю. Луценко; ассоциативные фотографические карты «Спектрокарты» У. Халкола и А. Копытина и др.), и МАК, в которых изображения связаны с одним метафорическим образом. Так, в качестве основного метафорического образа в наборах МАК часто используются изображения лиц людей (немецкие MAK М. Эгетмейера «PERSONA», «PERSONITA»), людей и зверей (украинские MAK Н. Верниковой «Люди и звери»). Для работы с метафорой жизненного пути часто выбираются изображения дорог, тропинок, автострад, шоссе, рек и др. (российские МАК «Пути-дороги. Метафора жизненного пути» Г. Кац и Е. Мухаматулиной; норвежские МАК Г. Сальпетер «Дороги» («Roads») и «Река» («The River»)). Метафору взаимодействия с внешним миром Г. Кац и Е. Мухаматулина представили через изображения разнообразных окон и дверей, а образ человека - 
через изображения деревьев (российские МАК «Окна и двери», «Дерево как образ человека» Г. Кац и Е. Мухаматулиной).

Одним из часто встречаемых в МАК образов является изображжение руки. Так, нам известны фотокарты Е. Тарариной «Колесо жизни» (фотограф Е. Сирик), представляющие из себя набор карточек с фотографиями рук и аффирмациями, позволяющими, по мнению автора, понять состояние основных сфер жизни человека (семья, личная жизнь, здоровье, карьера, друзья, отдых, досуг, саморазвитие). Также многие другие наборы МАК включают в себя отдельные картинки с изображениями рук (имеются в виду такие карты, в которых рука акцентирована, изображена крупным планом): немецкие «ОН», «СОРЕ», «MORENA», «SHEN HUA», «TAHITI»; «Спектрокарты» У. Халкола и A. Копытина; «Memory» Н. Глотовой и В. Меланич; «Сила времени» Н. Верниковой, «Кнуты и пряники» Т. Ушаковой и др.

Во многих случаях использование образа руки в изображениях МАК не обосновывается авторами в инструкциях и методических рекомендациях к ним, но есть и объяснения. Например, в немецких МАК «СОРЕ» изображения рук символизируют определенную жизненную стратегию преодоления кризисов. Считаем возможности использования метафоры руки в качестве проективного материала в работе психолога намного шире и глубже, поэтому и посвящаем данную статью анализу и систематизации очевидных и символических значений руки. Результаты данного теоретического анализа станут основой для научнопрактического обоснования возможностей использования метафоры руки (на примере МАК) в работе практического психолога.

\section{Методы исследования}

Теоретический анализ научной литературы по проблеме использования метафоры в психологической практике, обобщение и систематизация разнообразных исследований символики и значений руки; обобщение опыта использования изображения руки в практической психологии (на материале диагностических методов и разнообразных МАК); моделирование возможностей 
использования метафоры руки как проективного материала в работе психолога (на примере авторских МАК).

\section{Процедура исследования}

Теоретический анализ показал, что рука - это не только значимая и активная часть тела человека, которую М.Ф. Альбедиль характеризует как «природный совершенный биологический инструмент» и «едва ли не самый «говорящий» орган нашего тела, средство выражения чувств, знак действия» (Альбедиль, 2013: 155), но и определенный многозначный и многомерный символ, обладающий, по мнению М.Ф. Альбедиль, «почти бездонной смысловой глубиной, которую практически невозможно исчерпать какой-либо одной жестко фиксированной интерпретацией; в значительной мере она зависит от изменчивого культурного контекста» (Альбедиль, 2013: 171).

Изображение руки сопровождает человека с незапамятных времен и наделяется определенной символикой в мифологии, культуре, религии, искусстве, эзотерических учениях. Интересно, что семантическое поле разнообразных значений, связанных с руками, начало складываться по данным ученых, по меньшей мере, со времен палеолита. Как считает М.Ф. Альбедиль, первые изображения руки были частью древнего языка жестов, которые со временем приобрели символическое значение, т.к. им начали приписывать новый условный смысл: они стали изображать человека вообще (там же). Среди многообразных толкований первых исторических изображений руки нам наиболее близко понимание этих изображений как знаков присутствия человека в мире, что можно символически трактовать как проявление человеческого «Я» в земном существовании. Недаром в современных арт-терапевтических техниках одним из базовых и часто используемых упражнений на знакомство и самопрезентацию является работа с изображением собственной ладони, которую необходимо, например, обвести на листе бумаги, раскрасить ее отпечаток и т.д.

Расширить содержание метафоры руки позволяют результаты лексического, семантического и концептуального анализа. Так, лексема «рука» занимает первое 
место по частотности среди соматизмов, является одним из ста наиболее частотных слов русского языка; принадлежит активному словарю, входит в общеславянский фонд, обнаруживает широкие соответствия в индоевропейских языках; существительное «рука» относится к сверхмногозначным словам и входит в состав более чем 300 устойчивых выражений (Мыльникова, 2009: 157); обладает значительными слово- и фразеобразовательными возможностями (Попова, 204, 22; 2009: 265). Концепт «рука» рассматривается Н.В. Мыльниковой значимым компонентом концептосферы «человек». Концептуальное содержание «руки» включает в себя, по результатам ее исследования, телесный (рука как часть человеческого тела) и функиионально-деятельностный (рука как орудие деятельности) аспекты. По мнению исследователя, «в названных аспектах на разных уровнях абстракции концепт аккумулирует информацию о разнообразных телесных характеристиках рук, их ориентационной и орудийной функциях, а также о человеке во многих значимых аспектах его жизни и деятельности: предметной деятельности, труде, межличностных отношениях, психической жизни. Каждая сфера при разном ее осмыслении репрезентируется в категориях «деятельность», «отношение» и «состояние»» (Мыльникова, 2009: 4).

Огромное многообразие значений руки можно условно разделить на прямые (объективные, очевидные) и переносные (метафорические, символические). Объективные значения составляют характеристики руки как физического объекта (теплая-холодная, маленькая-большая, шершавая-гладкая) и органа тела (верхняя конечность человека, ладонь, предллечье, кисть); характеристики, указывающие на принадлежность руки человеку определенного пола (мужская-женская), возраста (рука ребенка, взрослого, человека пожилого возраста), социального положения (рука богатого и бедного), профессии (рука учителя, рука рабочего) и т.д. Кроме того, Н.В. Мыльникова в материально-телесном аспекте концептуального содержания руки выделяет: внешние качества рук (величина, толщина, форма, строение, характер кожного покрова, цвет); так называемые «активные» свойства рук как органа движения, действия (сила, физическая 
активность, состояние мускулов рук - крепость, гибкость, подвижность и т.д.); физические состояния рук (Мыльникова, 2009: 158).

Отметим, что метафорических и символических значений руки значительно больше. Рука часто рассматривается как символ власти (мирской и духовной), владычества, действия, силы, господства, помощи, покровительства, защиты, физической и моральной мощи, силы воли, способности совершать поступки; управления другими лицами; символ Бога, знак Божественного присутствия и активности (Мегаэнциклопедия Кирилла и Мефодия; Альбедиль, 2013; Попова, 2004, 2009); символ деятельности и труда (Попова, 2009); дружбы, любви, заботы, искренности (Мыльникова, 2009). Руки понимаются как главное орудие жизнедеятельности человека и его самых насущных действий (владения и зависимости, контакта и прикосновения; конкретных физических действий и манипуляций с объектом) (Мыльникова, 2009:12); как инструмент познания мира и себя; как единица измерения длины, объема, массы, эталон, с которым сопоставляются другие предметы (Мыльникова, 2009:11; Попова, 2009:271); как орудие воздействия на окружающий мир; как передатчик духовной и физической энергии. Символически слово «рука», по данным А.Р. Поповой, также связывается со стилем, почерком, творческой манерой; согласием на брак, готовностью вступить в брак (Попова, 2004). С помощью жестикуляции руками человек участвует в коммуникации, выражает свои чувства и состояния. По мнению исследователей, концепт «рука» способен аккумулировать информацию о внутренней, психической жизни, базовых эмоциях (любви, радости, беспокойстве, гневе, печали, страхе, отвращении) (Мыльникова, 2009:16-17).

Образ руки нашел свое применение и в практической психологии, в частности в проективной психодиагностике. Изображения руки были использованы в качестве визуальных стимулов в известной проективной методике «Наnd-тест» (тест «Руки») с целью выявления основных поведенческих тенденций человека (агрессия, директивность, аффектация, коммуникация, зависимость, страх, эксгибиционизм, калечность, напряжение, активные и пассивные 
безличные действия, галлюцинации и др.) на основании особенностей его индивидуального восприятия стимульного материала и ответов на вопрос: «Что делает эта рука?». При выборе стимульного материала авторы теста руководствовались тем, что превосходство человека над животными обусловлено уровнем развития человеческого мозга и человеческой руки. Так, рука, перестав выполнять функцию опоры при передвижении, приобрела большую свободу, в частности, стала вносить определяющий вклад в развитие мышления (связь между развитием функций руки и развитием умственных способностей подтверждена многочисленными исследованиями). Как отмечают авторы методики, «ни одна часть человеческого организма, за исключением глаз, не оказывает ему такой помощи в восприятии пространства и ориентации в нем, как рука, без чего, в свою очередь, невозможна организация любого действия» (Курбатова, Муляр, 2001: 3). Рука непосредственно вовлечена во внешнюю активность человека; обеспечивает кинестетическую и тактильную обратную связь; осуществляет постоянный контакт с внешней средой и помогает в выполнении разнообразных функций. Рука рассматривается как инструмент удовлетворения витальных потребностей и получения удовольствия (в том числе сексуального) (там же).

Как уже отмечалось, образ руки часто используется авторами МАК. Так, в немецких МАК «СОРЕ» («Преодоление») шесть метафорических изображений руки использованы для символического представления методов совладания со стрессом, стратегий и ресурсов преодоления кризисов и исцеления, описанных на основе разработанной М. Лаадом многомерной модели стилей «выживания» человека BASIC Ph. Каждая «рука» в МАК «СОРЕ» символизирует определенную жизненную стратегию:

- Чувства/аффект (умение распознавать различные чувства - как внутренние (бессознательные), так и открытые - и называть их своими собственными именами);

- Ум/познавательный, когнитивный фактор (способ преодоления кризисов, использующий наши ментальные способности, умение логически мыслить, 
оценивать ситуацию, постигать новые идеи, планировать, анализировать проблемы и решать их);

- Деятельность/физический и физиологический фактор (способ преодоления кризисов, обращающийся к деятельности нашего физического тела, физическая активность);

- Общуество/социальный фактор (способность к общению; социальная поддержка, принадлежность к сообществу, организации, принятие роли);

- Игра воображения и фантазии (творческие способности; использование творчества, ролевого проигрывания, облегчения, отвлечения);

- Вера/верования, убеждения и цеенности (умение верить - будь-то вера в Бога, в людей, в чудо или в себя самого; система убеждений; нахождение нового смысла) (Метафорические ассоциативные карты, «ОН Verlag»; Пергаменщик, 2015).

\section{Обсуждение результатов}

Проведенный теоретический анализ научной литературы, обобщение и систематизация разнообразных исследований символики и значений руки, обобщение опыта использования изображения руки в практической психологии (на материале диагностических методов и разнообразных МАК), а также собственный опыт психологической практики позволяют нам считать метафору руки важным проективным материалом в работе психолога и необходимым содержательным наполнением такого психологического терапевтического инструмента как МАК.

Необходимость в отдельном наборе МАК с изображениями рук осознавалась автором постепенно в ходе групповой и индивидуальной психологической работы с использованием различных метафор и, в частности, различных наборов МАК. Наиболее отчетливо идея о создании авторских МАК с изображениями рук стала оформляться при подготовке к метафорическому тренингу «Образ вальдорфской школы» для педагогов и родителей экспериментального учебного учреждения всеукраинского уровня СОШ №66 
(г. Запорожье), в которой на данный момент под нашим научным руководством экспериментально внедряется вальдорфская педагогика. В одном из упражнений участники должны были, работая в микрогруппах, составить из норвежских метафорических карт «Реки» и «Дороги» пути развития школы. Также задание предполагало описание действий педагогов, родителей и других внешних и внутренних «сил», с целью дальнейшего обсуждения влияния этих «сил» на развитие школы. Для данной процедуры очень хорошо должны были подойти карты с изображениями рук. Единственный известный нам на тот момент набор метафорических карт, полностью построенный на изображениях рук, «Колесо жизни» Елены Тарариной, не подошел, т.к. все фотокарты включали в себя, кроме изображений рук в разных комбинациях и положениях, различные слова и аффирмации, что придавало им слишком определенное значение, делая невозможным их использование в качестве проективного материала в данном упражнении. Благодаря тому, что во многих существующих наборах МАК присутствуют отдельные карты с изображениями рук, нам удалось для групповой работы из разных наборов МАК подобрать около двадцати изображений, чтобы задуманное упражнение состоялось. Но, для полноценного использования возможностей метафоры руки в психологической практике считаем недостаточным наличие нескольких изображений руки в наборах МАК. Смысловая многозначность и многомерность символа руки дает нам возможность разработать отдельный набор авторских МАК, полностью состоящий из различных изображений рук. Визуальным материалом для авторского набора МАК мы выбрали фотофрагменты картин известных художников прошлого, содержащие различные изображения рук.

Тестовая версия авторских МАК с изображением рук была апробирована в авторском метафорическом тренинге «Метафора жизненного пути», где с помощью изображений рук участникам необходимо было ответить на вопросы: «Кто/что оказывает влияние на мой жизненный путь? Как это сказывается на мне и моей жизни?». Свою эффективность тестовый набор МАК также подтвердил в 
работе с образом-Я и образом значимого Другого, с актуальными психическими состояниями человека, с проблемами взаимоотношений и др. Как показала наша практика, образ руки оказался благоприятным для ассоциирования с внутренними и внешними действиями человека, с жизненными препятствиями и ресурсами.

Таким образом, на основе проведенного теоретического исследования и опыта практической работы предлагаем рабочую модель направлений психологических запросов, в работе с которыми психолог может использовать МАК «Руки», учитывая основные смысловые и символические характеристики руки. Отметим, что, более глубокое понимание значений и символики руки необходимо психологу не для того, чтобы навязывать клиенту те или иные фиксированные смыслы, объяснять символику и т.д., а для того, чтобы расширить возможности использования метафоры руки в своей работе. Ориентируясь в различных значениях руки, психолог может более осознанно задействовать данную метафору при работе с самым разным кругом проблем, создавая необходимые для этого условия, например, своими вопросами клиенту в работе с тем или иным проективным изображением. Т.е. известное специалистам по МАК условие, что «хозяином» истории и возникающих образов и ассоциаций по метафорической карте является сам клиент, сохраняется.

Задействование в психологической практике очевидных (объективных) характеристик руки позволит работать с:

- проблемами физического здоровья и самочувствия, образом тела и его принятием, психомоторным тонусом (различные физические состояния руки как органа тела человека; «активные» свойства рук как органа движения, действия); - проблемами возрастного развития и старения, личностной зрелости (изображения рук людей разного возраста);

- проблемами взаимоотношений: парных (изображения рук мужчин $u$ женщин); детско-родительских (изображения рук взросльх и детей) и др.; 
- проблемами социализации, социального и профессионального статуса (изображения рук «богатых» и «бедных», представителей разных профессий); социальными ролями.

Задействование в психологической практике символических характеристик руки позволит работать с:

- проблемами власти (субъектами власти можно рассматривать Бога, время, судьбу, провидение, другого человека, предмет и т.д.) и подчинения; насилия; покровительства, помощи, защиты и наказания; проблемами обладания кем-либо или чем-либо;

- проблемами, связанными с предметной и непредметной (социальные и межличностные отношения, психическая деятельность) деятельностью человека, разными видами активности, трудом и работой, творчеством и т.д.;

- травматичным опытом; выработкой методов совладания со стрессом, стратегий преодоления кризисов; ресурсами и препятствиями; поиском источника жизненных сил и энергии;

- проблемами гармонизации и балансирования разных сторон жизни;

- проблемами психического и психологического здоровья, психическими состояниями; образом «Я»; субличностями; самооценкой и т.д.;

- проблемами удовлетворения потребностей, в том числе сексуальных; мотивацией;

- развитием навыков самопрезентации и коммуникативных способностей;

- экзистенциальными, нравственными и ценностно-смысловыми вопросами (дихотомия рук на правую и левую позволит, например, выйти на обсуждение проблем добра и зла в жизни человека; через обсуждение дающей функции руки можно выйти на тему Служения в жизни человека).

\section{Выводы}

Таким образом, в ходе теоретического рассмотрения нами обосновано обращение психологов к метафорическому, образному и символическому материалу. Наряду со всеми другими важными особенностями метафоры мы 
делаем акцент на ее понимании как средстве выражения, опредмечивания и конструирования смыслов, в том числе экзистенциальных. Считаем метафору в работе психолога проективным и терапевтическим инструментом. На примере содержательного наполнения МАК поднимаем проблему научно-практического обоснования метафорических образов, используемых в психологической практике. Рассматриваем метафору руки важным проективным материалом в работе психолога и необходимым содержательным наполнением такого психологического терапевтического инструмента как МАК. В результате обобщения и систематизации разнообразных исследований символики и значений руки, обобщения опыта использования изображений руки в практической психологии (на материале диагностических методов и разнообразных МАК), а также на основе собственного разнообразного опыта практической работы мы предложили рабочую модель возможностей использования метафоры руки как проективного материала в работе психолога (на примере авторских МАК). Учитывая многозначность, многомерность и относительную универсальность метафоры руки, полагаем, что задействование в психологической практике очевидных (объективных) и символических характеристик руки позволит работать с большим репертуаром психологических запросов.

Перспективы дальнейших исследований связаны с уточнением рабочей модели возможностей использования метафоры руки как проективного материала в работе практического психолога; проведением ряда психосемантических исследований значений слова «рука» на разных выборках испытуемых; детальным описанием авторских МАК с изображениями рук как проективного инструмента в работе практического психолога на основе разнообразного опыта практической индивидуальной и групповой работы.

\section{СПИСОК ЛИТЕРАТУРЫ/ REFERENCES}

Альбедиль М. Ф. «Ты держишь мир в простертой длани»: символика руки / М. Ф. Альбедиль // Теория моды. - М.: Новое литературное обозрение, 2013, № 
27 (Весна). - С. 155-172. [Электронный ресурс]. - Режим доступа: http://www.nlobooks.ru/node/3296.

Albedil, M.F. (2013). «Ty derjish mir v prostertoi dlani»: simvolika ruki [«You hold the world in the pro erased hand»: hand's symbolics]. Teoriia mody - The fashion theory, 27, 155-172. Retrieved from http://www.nlobooks.ru/node/3296 [in Russian].

Анастази А. Психологическое тестирование / А.Анастази, С.Урбина. - СПб.: Питер, 2001. - 688 с.

Anastazi, A., \& Urbina, S. (2001). Psikhologicheskoe testirovanie [Psychological testing]. Sankt-Petersburg: Piter [in Russian].

Вачков И.В. Метафорический тренинг / Вачков И.В. - [2-е изд.]. - М.: «Ось-89», 2006. - 144 с.

Vachkov, I.V. (2006). Metaforicheskii trening [Metaphorical training]. Moskva: «Os-89» [in Russian].

Курбатова Т.Н. Проективная методика исследования личности «Наnd-тест». Методическое руководство / Т.Н. Курбатова, О.И. Муляр. - СПб, ГМНППП «ИМАТОН», $2001-64$ c.

Kurbatova, T.N., \& Muliar, O.I. (2001). Proektivnaia metodika issledovaniia lichnosti «Hand-test» [Projective technique of research of the person «Hand-test»]. Sankt-Petersburg: «IMATON» [in Russian].

Метафорические ассоциативные карты. Руководство к применению. Издательство «ОН Verlag». - [Электронный ресурс]. - Режим доступа: http://pushkov.com.ua/oh-cards/item/53-instrukcii-k-katam.html.

Metaforicheskie assotsiativnue karty. Rukovodstvo $\mathrm{k}$ primeneniiu [The Metaphoric Cards. Guidance for the use] Germany: «OH Verlag». Retrieved from http://pushkov.com.ua/oh-cards/item/53-instrukcii-k-katam.html. [in Russian].

Міхіна I.M. Розвиток творчих здібностей дошкільників засобами терапевтичної метафори: автореф. на здобуття наук. ступеня канд. психол. наук: спец. 19.00.07 «Педагогічна та вікова психологія» / І.М. Міхіна. - 2003. - 23 с. 
Mikhina, I.M. (2003). Rozvytok tvorchykh zdibnostei doshkilnykiv zasobamy terapevtychnoi metafory [Development of creation in under school age children by means of therapeutic metaphors]: Ehtended abstract of candidate's thesis [in Ukrainian].

Мыльникова Н.В. Структура и функционирование концепта «рука» в русском языке: автореф. дис. на соискание учен. степени канд. филол. наук: спец. 10.02.01 «Русский язык» / Н.В. Мыльникова. - Самара, 2009. - 20 с.

Mylnikova, N.V. (2009). Struktura i funktsionirovanie kontsepta «ruka» v russkom yazyke [Structure and functioning concept «hand» in Russian] Ehtended abstract of candidate's thesis. Samara [in Russian].

Мыльникова Н.В. Функциональный аспект содержания концепта «рука» / Н.В. Мыльникова // Вестник Самарского государственного университета. - 2009. - № 67. - С. 157-163 [Электронный ресурс]. - Режим доступа: http://cyberleninka.ru/article/n/funktsionalnyy-aspekt-soderzhaniya-kontsepta-ruka

Mylnikova, N.V. (2009). Funktsionalnyi aspekt soderjaniia kontsepta «ruka» [Functional aspect of the maintenance concept «hand»] Vestnik Samarskogo gosudarstvennogo universiteta - The bulletin of the Samara state university, 67, 157163. Retrieved from http://cyberleninka.ru/article/n/funktsionalnyy-aspektsoderzhaniya-kontsepta-ruka [in Russian].

Ортега-и-Гассет Х. Две великие метафоры / Х.Ортега-и-Гассет // Теория метафоры: сборник / под общ. ред. Н. Д. Арутюновой и М.А. Журинской. - М.: Прогресс, 1990. - С. 68-82.

Ortega-i-Gasset, Kh. (1990) Dve velikie metafory [Two great metaphors] In: The metaphor theory: the collection, (pp. 68-82). Moskva: Progress. [in Russian].

Пезешкиан Н. Психотерапия повседневной жизни: тренинг разрешения конфликтов / Пезешкиан Н. - СПб.: Речь, 2001. - 228 с.

Pezeshkian, N. (2001) Psikhoterapia povsednevnoi jizni: trening razrecheniia konfliktov [Psychotherapy of a daily life: training to resolve conflicts]. SanktPetersburg: Rech [in Russian]. 
Пергаменщик Л.А. Теоретические основания кризисной психологии / Л.А. Пергаменщик // Личность в экстремальных условиях и кризисных ситуациях жизнедеятельности. - Владивосток: Центр клинической и прикладной психологии. - 2015. - № 5. - С. 92-100 [Электронный ресурс]. - Режим доступа: http://elib.bspu.by/handle/doc/9116.

Pergamenshchik, L.A. (2015). Teoreticheskiie osnovaniia krizisnoi psikhologii [The theoretical basis of the crisis psychology]. Lichnost $\mathrm{v}$ ekstremalnykh usloviiakh $\mathrm{i}$ krizisnykh situatsiiakh zhiznedeiatelnosti - The person in extreme conditions and crisis situations of ability to live, 5, 92-100 Retrieved from http://elib.bspu.by/handle/doc/9116. [in Russian].

Попова А.Р. Полисемант рука и реализация его лексикофразеообразовательных возможностей в русском языке: автореф. дис. на соискание учен. степени канд. филол. наук: спец. 10.02.01 «Русский язык» / А.Р. Попова. - Орел, 2004. - 28 с.

Popova, A.R. (2004) Polisemant ruka i realizatsiia ego leksikofrazeobrazovatelnykh vozmojnostei $\mathrm{v}$ russkom yazyke [Polysemant $a$ hand and its realisation lexical \& phraseological possibilities in Russian]. Ehtended abstract of candidate's thesis. Orel [in Russian].

Попова А.Р. Фразеообразовательный потенциал полисемантичной лексемы и его реализация в национальном русском языке (на примере существительного рука) / А.Р. Попова // Вестник Челябинского государственного педагогического университета. - 2009. - №5. - С. 264-277 [Электронный ресурс]. - Режим доступа: http://cyberleninka.ru/article/n/frazeoobrazovatelnyy-potentsial-polisemantichnoyleksemy-i-ego-realizatsiya-v-natsionalnom-russkom-yazyke-na-primere.

Popova, A.R. (2009). Frazeobrazovatelnyi potentsial polisemanticheskoi leksemy i ego realizatsiia $\mathrm{v}$ natsionalnom russkom yazuke (na primere sushchestvitelnogo ruka) [Phraseological potential polysemantic lexemes and its realisation in national Russian (on an example of a noun $a$ hand) / Vestnik Cheliabinskogo gosudarstvennogo pedagogicheskogo universiteta - The bulletin of the Chelyabinsk state pedagogical 
university, 5 ,

http://cyberleninka.ru/article/n/frazeoobrazovatelnyy-potentsial-polisemantichnoyleksemy-i-ego-realizatsiya-v-natsionalnom-russkom-yazyke-na-primere. [in Russian].

Рука (символ) // Мегаэнциклопедия Кирилла и Мефодия [Электронный pecypc].

http://megabook.ru/article/\%D0\%A0\%D1\%83\%D0\%BA\%D0\%B0\%20(\%D1\%81\%D0 \%B8\%D0\%BC\%D0\%B2\%D0\%BE\%D0\%BB).

Ruka (simvol) [Hand (symbol)]. Megaentsiklopediia Kirilla i Mefodiia - Cyril's \& Mefodiy's megaencyclopedia Retrieved from http://megabook.ru/article/\%D0\%A0\%D1\%83\%D0\%BA\%D0\%B0\%20(\%D1\%81\%D0 \%B8\%D0\%BC\%D0\%B2\%D0\%BE\%D0\%BB). [in Russian].

Свирепо О. А. Образ, символ, метафора в современной психотерапии / О. А. Свирепо, О. С.Туманова. - М.: Изд-во Института Психотерапии, 2004. - 270 с.

Svirepo, O. A., \& Tumanova, O.S. (2004). Obraz, simvol, metafora v sovremennoj psikhoterapii [Image, symbol, metaphor in the modern psychotherapy]. Moskva: Izd-vo Instituta Psikhoterapii. [in Russian].

Шрагіна Л.І. Психологія вербальної уяви: функціонально-системний підхід. Монографія / Л.І. Шрагіна. - К.: Вид. дім «Києво-Могилянська академія», 2016. $284 \mathrm{c}$.

Shragina, L.I. (2016). Psykhologiia verbalnoi uiavy: funktsionalno-systemnyi pidkhid [The psychology of verbal imagination: the functional system approach. The monography]. Kyiv: Vyd.dim «Kyevo-Mogylianska akademiia». [in Ukrainian]. 